\title{
PERDAS NA COLHEITA MECANIZADA DE SOJA NO ESTADO DE MINAS GERAIS
}

\section{MARCO A. O. CAMPOS ${ }^{1}$, ROUVERSON P. DA SILVA ${ }^{2}$, ALBERTO CARVALHO FILHO $^{3}$, HUGO C. B. MESQUITA ${ }^{1}$, SAMIR ZABANI ${ }^{1}$}

RESUMO: O presente trabalho teve por objetivo avaliar as perdas na colheita de soja em função da idade, velocidade de trabalho, sistema de trilha (axial e radial) e condição de propriedade das colhedoras (própria ou alugada), nas regiões do Triângulo Mineiro e Alto Paranaíba - MG, durante a colheita de soja da safra 2002-2003. A velocidade de trabalho das colhedoras e a rotação do cilindro de trilha também foram estudadas, à exceção de quando avaliadas como variável-função. Os resultados obtidos permitiram concluir que as perdas de grãos independem da velocidade das colhedoras e que as colhedoras com até cinco anos, independentemente da sua taxa de utilização anual, tiveram menores perdas do que as colhedoras com mais de seis anos. As colhedoras próprias apresentaram menores perdas comparadas com as alugadas, e as máquinas com sistema de trilha axial apresentaram menores perdas do que aquelas com sistema de trilha radial.

PALAVRAS-CHAVE: sistema de trilha, colhedoras, velocidade de trabalho.

\section{LOSSES IN THE SOYBEAN MECHANICAL HARVESTING IN MINAS GERAIS STATE, BRAZIL}

ABSTRACT: This work aimed the evaluation of soybean mechanical harvesting in Minas Gerais State, during 2002/2003 soybean crop, comparing grain losses according to harvester age, harvesting ground speed, track system (axial and radial) and property condition (proper or rented). Ground speed and tracking cylinder rotation were also studied except when they were evaluated as variable function. The results indicate that the harvesters up to five years old, independent of their rate of annual use, had lesser losses than the harvesters with more than six years. The proper harvesters had presented minors losses when comparing with rented and the machines with axial track system presented minors losses than those with radial track system.

KEYWORDS: track system, harvesters, ground speed.

\section{INTRODUÇÃO}

O Triângulo Mineiro e Alto Paranaíba constituem as regiões com maior produção de grãos de Minas Gerais, e sua alta produção deve-se ao bom nível tecnológico dos seus produtores, que utilizam práticas modernas, possibilitando o emprego de alta tecnologia na colheita de grãos. Por ser uma das principais etapas do processo de produção, a colheita torna-se uma operação muito importante, sendo necessário bom desempenho visando a reduzir as perdas nesse processo.

SALES \& CONSTANTIN (2000) relatam que o Brasil perde aproximadamente 1,5 milhão de toneladas com a colheita de soja, sendo parte dessas perdas provocada pela presença de plantas daninhas que, dependendo do nível de infestação, pode aumentar a quantidade de material estranho colhido, dificultando a trilha, separação e limpeza no processo de colheita. Além disso, as plantas daninhas podem provocar vibração nas plantas de soja no recolhimento, pelo fato de se entrelaçarem

\footnotetext{
${ }^{1}$ Eng $^{\mathrm{o}}$ Agr ${ }^{\mathrm{o}}$, Grupo JM, 5ª Avenida, 113, Centro, Mineiros - GO, marcogjm@ hotmail.com

${ }^{2}$ Prof. Dr., Departamento de Engenharia Rural, UNESP, Jaboticabal - SP, rouverson@ @cav.unesp.br.

${ }^{3}$ Prof. Dr., Faculdades Associadas de Uberaba, alberto@fazu.br

Recebido pelo Conselho Editorial em: 23-10-2003

Aprovado pelo Conselho Editorial em: 20-4-2005
}

Eng. Agríc., Jaboticabal, v.25, n.1, p.207-213, jan./abr. 2005 
nessas plantas durante a ação giratória do caracol. Essas plantas daninhas podem ocasionar até $80 \%$ das perdas totais da colhedora durante a colheita.

Avaliando o perfil da colheita mecanizada de soja no Brasil, na safra 1998-1999, MESQUITA et al. (2002) encontraram relação entre a idade de uso da colhedora e o nível de perdas na colheita, observando que as máquinas com mais de 15 anos de idade apresentaram perdas superiores àquelas encontradas nas colhedoras com menos de cinco anos de idade. Entretanto, os autores encontraram, também, elevado número de colhedoras com mais de 15 anos com perdas abaixo de 1 saco ha ${ }^{-1}$, indicando que outros fatores, tais como eficiência do operador, condições da lavoura e conservação da máquina podem ter mais influência sobre o nível de perdas.

MESQUITA et al. (1998) afirmam que o sistema de trilha na colheita da soja provoca quebra de pequenos fragmentos nos grãos e que, muitas vezes, esses danos não são percebidos nos restos culturais ou até em medições de perdas. As perdas com a quebra dos grãos representam de $1,7 \%$ a 14,5\% das perdas na colheita. De acordo com MESQUITA et al. (2002), colhedoras que possuem sistema de trilha longitudinal ou axial apresentam menores danos mecânicos às sementes quando comparados com sistema de trilha radial.

SKROMME (1977), citado por COSTA et al. (2002b), confirma que as colhedoras axiais possuem maior capacidade de colheita e apresentam redução de danos mecânicos às sementes, embora ainda apresentem um custo de aquisição considerado elevado para os produtores brasileiros.

Para ALVES SOBRINHO \& HOOGERHEIDE (1998), outro importante fator que pode dificultar a redução das perdas na colheita de soja é a baixa escolaridade dos operadores, aliada à falta de treinamento dos mesmos. Além disso, os autores afirmam que a redução das perdas pode ser obtida se os produtores fizerem monitoramento constante da colheita.

COSTA et al. (2002b) afirmam que a alta variabilidade encontrada em estudos da qualidade de sementes durante a colheita demonstram que as causas estão relacionadas a fatores como manutenção deficiente e regulagens inadequadas das colhedoras, além da ocorrência de chuvas durante o período de colheita.

Este trabalho teve por objetivo avaliar as perdas dos grãos de soja (Glycine max) em lavouras das regiões do Triângulo Mineiro e Alto Paranaíba, na safra 2002-2003, em função da idade de uso das colhedoras, velocidade de trabalho, sistema de trilha (axial ou radial) e condição de propriedade das colhedoras (própria ou alugada).

\section{MATERIAL E MÉTODOS}

O trabalho foi realizado em dez propriedades produtoras de soja, avaliando-se as perdas em 21 colhedoras nas regiões do Triângulo Mineiro e Alto Paranaíba, durante março a maio de 2003. As propriedades e as colhedoras foram selecionadas de acordo com o perfil da mecanização agrícola regional (SILVA et al., 1998).

Os dados foram coletados utilizando-se da metodologia do copo medidor, a qual associa o volume de grãos perdidos em sacos ha ${ }^{-1}$ em uma escala graduada desenvolvida por MESQUITA et al. (1982), citado por MESQUITA et al. (2001b). Foram mensuradas as perdas de soja em sacos ha ${ }^{-1}$ por meio da coleta de todos os grãos e vagens caídos no solo, dentro de armação de madeira e barbante de $2 \mathrm{~m}^{2}$, com comprimento igual à largura da plataforma de corte. As vagens encontradas foram debulhadas e colocadas no copo medidor juntamente com os grãos soltos coletados. Foram coletadas amostras constituindo quatro repetições para cada colhedora avaliada, com distâncias de $50 \mathrm{~m}$ entre as amostras, caracterizando um delineamento inteiramente casualisado. As perdas foram determinadas antes do início da colheita (perdas pré-colheita), colocando-se a armação em áreas não colhidas e após 
a passagem da colhedora (perdas totais). As perdas de cada máquina foram obtidas por meio da diferença entre as perdas totais e de pré-colheita.

Os dados foram anotados em planilhas com campos para anotação do ano de fabricação, rotação do cilindro, abertura do côncavo, perdas, condição de propriedade (próprias ou alugadas), sistema de trilha (axial ou radial), marca e modelo das colhedoras. Para a obtenção dos valores da rotação e velocidade de deslocamento, acompanhou-se o operador em um percurso equivalente ao comprimento do talhão durante a colheita, anotando-se na planilha as leituras realizadas no painel das máquinas. Para as colhedoras mais antigas, que não possuíam velocímetro, determinou-se a velocidade cronometrando-se o tempo de percurso em $10 \mathrm{~m}$ com três repetições, obtendo-se a velocidade média de deslocamento. O teor de água dos grãos foi obtido por meio de aparelho digital portátil, no momento da colheita. Já a idade da colhedora foi obtida por meio de pergunta direta ao responsável pela colheita, em consulta aos manuais ou conferência na chapa afixada na colhedora com o ano de fabricação. Os modelos de colhedora utilizados são apresentados na Tabela 1.

TABELA 1. Especificação das colhedoras estudadas.

\begin{tabular}{lcrcc}
\hline \multirow{2}{*}{ Colhedora } & \multicolumn{2}{c}{ Idade } & Sistema de & Condição de \\
\cline { 2 - 3 } JD 1550 & Anos & Horas & Trilha & Propriedade \\
JD STS 9650 & 0 & 260 & Radial & Própria \\
MF 5650 Ad & 0 & 226 & Axial & Própria \\
JD 1550 & 0 & 300 & Radial & Alugada \\
CASE 2388 & 0 & 421 & Radial & Própria \\
MF 34 & 1 & 849 & Axial & Própria \\
MF 34 & 3 & 1.588 & Radial \\
SLC 1175 & 3 & 1.607 & Radial & Própria \\
NH TC 57 & 4 & 1.840 & Radial & Alugada \\
MF 3640 & 9 & 2.150 & Radial & Própria \\
SLC 1175 & 5 & 2.290 & Radial & Própria \\
NH 8040 & 7 & 2.809 & Radial & Própria \\
NH TC 57 & 11 & 3.115 & Radial & Própria \\
SLC 7500 & 9 & 4.216 & Radial & Própria \\
NH TC 57 & 9 & 4.477 & Radial & Própria \\
SLC 1175 & 9 & 5.173 & Radial & Alugada \\
SLC 7200 & 12 & Radial & Alugada \\
MF 3640 & 14 & Radial & Alugada \\
MF 3640 & 14 & 6.400 & Radial & Alugada \\
SLC 2200 & 14 & 6.300 & Radial & Alugada \\
SLC 6200 & 22 & 6.490 & Radial & Alugada \\
\hline
\end{tabular}

Utilizando o programa ANOVA $^{\circledR}$, foram realizadas análises de variância com um fator de classificação e aplicado o teste de Tukey, a 5\% de probabilidade, para comparar as perdas de grãos em função da velocidade de deslocamento, rotação do cilindro, idade de uso das colhedoras, sistema de trilha e condição de propriedade. Devido ao agrupamento de dados realizados, o número de amostras foi diferente para cada parâmetro analisado, sendo mostrados no rodapé das Tabelas.

\section{RESULTADOS E DISCUSSÃO}

Na Tabela 2, observa-se que máquinas com idade entre zero e cinco anos apresentaram menores valores de perdas para a cultura da soja do que aquelas com mais de seis anos de idade. A velocidade 
de deslocamento da colhedora e a rotação do cilindro não foram influenciadas pela idade de uso das máquinas. Resultados semelhantes foram obtidos por MESQUITA et al. (2002) e por MESQUITA et al. (2001a), que também encontraram altos valores para o coeficiente de variação, valores esses justificados pela alta variabilidade da amostra observada em vários estudos sobre perdas na colheita realizados em condições de campo.

TABELA 2. Perdas de grãos, velocidade de deslocamento e rotação do cilindro em função da idade das colhedoras.

\begin{tabular}{lccc}
\hline Idade $($ anos $)$ & Perdas $^{1}\left(\right.$ sacos ha $\left.^{-1}\right)$ & Velocidade $^{2}\left(\mathrm{~km} \mathrm{~h}^{-1}\right)$ & Rotação do Cilindro $^{3}(\mathrm{rpm})$ \\
\hline 0 a 5 & $1,2 \mathrm{~b}$ & $6,6 \mathrm{a}$ & $796 \mathrm{a}$ \\
6 a 10 & $1,9 \mathrm{a}$ & $6,1 \mathrm{a}$ & $790 \mathrm{a}$ \\
>10 & $1,9 \mathrm{a}$ & $6,4 \mathrm{a}$ & $787 \mathrm{a}$ \\
\hline Teste F & $10,15^{*}$ & 0,27 n.s. & 0,01 n.s. \\
C.V. $(\%)$ & 44,75 & 18,81 & 17,07 \\
\hline
\end{tabular}

${ }^{1}$ Número de amostras para perdas: 0 a 5 anos de idade, 32 amostras; 6 a 10 anos de idade, 20 amostras; $>10$ anos de idade, 32 amostras. ${ }^{2}$ Número de amostras para velocidade: 0 a 5 anos de idade, 8 amostras; 6 a 10 anos de idade, 5 amostras; $>10$ anos de idade, 8 amostras. ${ }^{3}$ Número de amostras para rotação do cilindro: 0 a 5 anos de idade, 8 amostras; 6 a 10 anos de idade, 5 amostras; $>10$ anos de idade, 8 amostras.

Médias seguidas de mesma letra nas colunas indicam que os resultados não diferiram entre si, pelo teste de Tukey, a 5\% de probabilidade.

Na Figura 1, apresenta-se a curva de tendência das perdas médias em função da idade de uso das máquinas. As colhedoras mais novas, de 0 a 5 anos, apresentaram menores perdas, porém ao se analisar as colhedoras mais antigas, de 6 a 10 anos e com mais de 10 anos, observa-se que a idade não foi motivo relevante para a ocorrência de perdas, o que se explica devido à ação de outros fatores, tais como o estado de conservação da máquina, a taxa de utilização anual e a eficiência do operador também influenciam nas perdas na colheita, como afirmam ALVES SOBRINHO \& HOOGERHEIDE (1998).

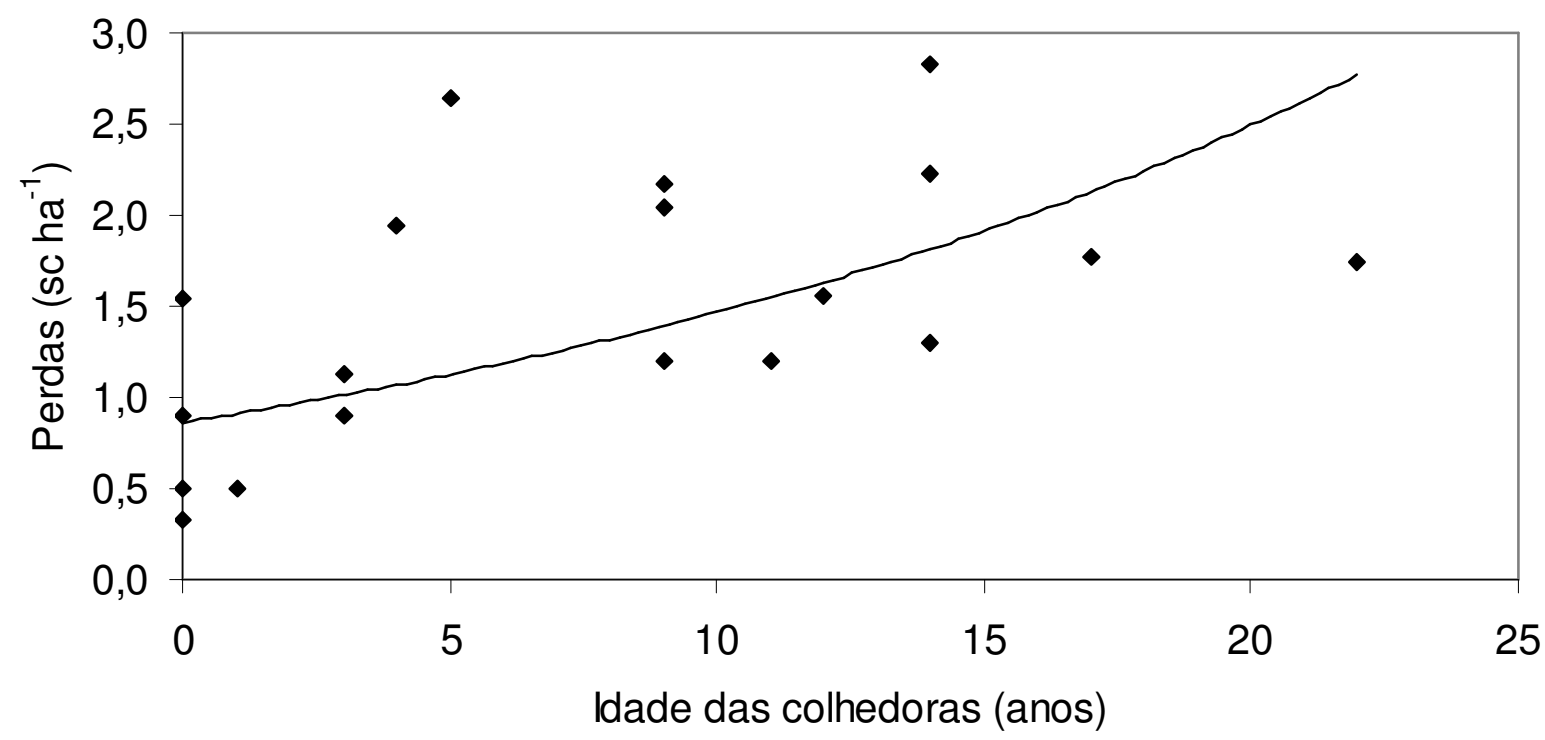

FIGURA 1. Perdas de grãos resultantes da colheita da soja em função da idade de uso das colhedoras.

Além desses fatores, outro de igual importância a ser observado é a velocidade de deslocamento. $\mathrm{Na}$ Tabela 3, percebe-se que, para as condições estudadas, a velocidade de deslocamento não influenciou significativamente nas perdas de grãos, o que discorda dos resultados obtidos por 
MESQUITA et al. (2001a), que afirmam haver tendência de menores perdas quando as colhedoras operam em velocidades abaixo de $7 \mathrm{~km} \mathrm{~h}^{-1}$. A falta de relação direta entre a velocidade de deslocamento e as perdas na colheita é possivelmente explicada pelo alto valor do coeficiente de variação encontrado na determinação de perdas em condições de campo.

Quanto à rotação do cilindro (Tabela 3), também não foram encontradas diferenças significativas, discordando também dos resultados encontrados por MESQUITA et al. (2002). A velocidade de deslocamento e a rotação do cilindro de trilha são fatores fortemente dependentes da regulagem promovida pelo operador, que, nas colhedoras analisadas, seguiu orientações dos proprietários das colhedoras (serviço próprio ou terceirizado). A regulagem, quando realizada de forma adequada, torna-se um fator decisivo para a redução ou aumento das perdas.

TABELA 3. Perdas de grãos e rotação do cilindro em função da velocidade de deslocamento.

\begin{tabular}{ccc}
\hline Velocidade $\left(\mathrm{km} \mathrm{h}^{-1}\right)$ & Perdas $^{1}\left(\mathrm{sacos} \mathrm{ha}^{-1}\right)$ & Rotação do Cilindro $^{2}(\mathrm{rpm})$ \\
\hline 4 a 6 & $1,2 \mathrm{a}$ & $718 \mathrm{a}$ \\
6 a 7 & $1,4 \mathrm{a}$ & $814 \mathrm{a}$ \\
7 a 9 & $1,7 \mathrm{a}$ & $850 \mathrm{a}$ \\
\hline F & 1,14 n.s. & 2,53 n.s. \\
C.V. & $49,36 \%$ & $15,09 \%$ \\
\hline
\end{tabular}

${ }^{1}$ Número de amostras para perdas: 4 a $6 \mathrm{~km} \mathrm{~h}^{-1}, 32$ amostras; 6 a $7 \mathrm{~km} \mathrm{~h}^{-1}, 20$ amostras; $>7 \mathrm{~km} \mathrm{~h}^{-1}, 32$ amostras.

${ }^{2}$ Número de amostras para rotação do cilindro: 4 a $6 \mathrm{~km} \mathrm{~h}^{-1}, 8$ amostras; 6 a $7 \mathrm{~km} \mathrm{~h}^{-1}, 5$ amostras; $>7 \mathrm{~km} \mathrm{~h}^{-1}, 8$ amostras.

Médias seguidas de mesma letra nas colunas indicam que os resultados não diferiram entre si, pelo teste de Tukey, a 5\% de probabilidade.

A condição de trabalho da máquina (própria ou terceirizada), mostrada na Tabela 4, influenciou significativamente nas perdas de grãos, sendo as perdas apresentadas pelas colhedoras alugadas 108,9\% superiores ao nível considerado aceitável, que, segundo MESQUITA et al. (2001b), é de 1 saco $^{-1}{ }^{-1}$. Já as colhedoras próprias apresentaram perdas $34 \%$ superiores ao nível aceitável. A diferença entre colhedoras terceirizadas e próprias confirma os resultados encontrados por SILVA et al. (2002), sendo explicada pelo maior cuidado exigido pelo proprietário na condução da colheita, enquanto, nas máquinas terceirizadas, não se registram os mesmos cuidados durante a colheita. Outros fatores analisados não diferiram significativamente em relação à condição de trabalho das máquinas.

TABELA 4. Perdas de grãos, velocidade de deslocamento e rotação do cilindro em função da condição de propriedade das colhedoras.

\begin{tabular}{cccc}
\hline Condição de Propriedade & Perdas $^{1}\left(\mathrm{saco} \mathrm{ha}^{-1}\right)$ & Velocidade $^{2}\left(\mathrm{~km} \mathrm{~h}^{-1}\right)$ & Rotação do Cilindro $^{3}(\mathrm{rpm})$ \\
\hline Alugada & $2,1 \mathrm{~b}$ & $6,8 \mathrm{a}$ & $805 \mathrm{a}$ \\
Própria & $1,3 \mathrm{a}$ & $6,2 \mathrm{a}$ & $780 \mathrm{a}$ \\
\hline F & $21,8^{*}$ & 1,78 n.s. & 0,18 n.s. \\
C.V. & $43,96 \%$ & $17,76 \%$ & $16,54 \%$ \\
\hline
\end{tabular}

${ }^{1}$ Número de amostras para perdas: alugada 36 amostras; própria 48 amostras.

${ }^{2}$ Número de amostras para velocidade: alugada 9 amostras; própria 12 amostras.

${ }^{3}$ Número de amostras para rotação do cilindro: alugada 9 amostras; própria 12 amostras.

Médias seguidas de mesma letra nas colunas indicam que os resultados não diferiram entre si, pelo teste de Tukey, a 5\% de probabilidade.

Quanto aos sistemas de trilha axial e radial (Tabela 5), foram encontradas diferenças significativas para as médias de grãos perdidos, com as colhedoras de fluxo axial apresentando menores perdas quando comparadas com as colhedoras radiais. As perdas encontradas nas máquinas de fluxo axial permaneceram no nível tolerável para a cultura da soja, enquanto as colhedoras de fluxo 
radial, em todas as faixas de rotação observadas, as perdas foram superiores ao nível de 1 saco ha $^{-1}$, considerado aceitável para colheita de soja. Esses resultados demonstram que as colhedoras de fluxo axial proporcionam menores perdas na colheita, pois possibilitam que a palha permaneça mais tempo dentro da máquina, melhorando a eficiência do sistema de trilha, como afirma MACHADO (2004). Aliado às menores perdas encontradas nas colhedoras de fluxo axial tem-se o fato de que, por trabalharem em menor rotação do cilindro trilhador, essas máquinas apresentaram menor exigência de potência (KUTZBACH, 1996; HUISMAN, 1983, citado por MESQUITA \& HANNA, 1993). Observa-se ainda que as colhedoras de fluxo radial apresentaram menores perdas na faixa de rotação de 800 a $900 \mathrm{rpm}$, quando comparadas com colhedoras radias trabalhando com rotação do cilindro de 700 a $800 \mathrm{rpm}$, diferindo dos resultados de COSTA et al. (2002a), que encontraram maiores perdas na colheita de sementes de soja para maior rotação do cilindro trilhador. Entretanto, esses autores, ao utilizarem maior rotação do cilindro, trabalharam com velocidade acima da recomendada para as colhedoras analisadas. A redução de perdas em rotações maiores do cilindro das colhedoras radiais se justifica pela maior dificuldade de trilha encontrada em rotações mais baixas nessas colhedoras, como afirmam COSTA \& TAVARES (1995), citados por PINHEIRO NETO \& GAMERO (1999).

TABELA 5. Perdas de grãos, velocidade de deslocamento e rotação do cilindro em função do sistema de trilha.

\begin{tabular}{lcc}
\hline \multicolumn{1}{c}{ Sistema de Trilha } & Perdas $^{1}\left(\mathrm{saco} \mathrm{ha}^{-1}\right)$ & Velocidade $^{2}\left(\mathrm{~km} \mathrm{~h}^{-1}\right)$ \\
\hline Axial & $0,44 \mathrm{a}$ & $6,33 \mathrm{a}$ \\
Radial (700 a 800 rpm) & $2,01 \mathrm{c}$ & $6,19 \mathrm{a}$ \\
Radial (800 a 900 rpm) & $1,64 \mathrm{~b}$ & $6,84 \mathrm{a}$ \\
\hline F & $30,848^{*}$ & $0,635^{*}$ \\
C.V. & $36,840 \%$ & $19,028 \%$ \\
\hline
\end{tabular}

${ }^{1}$ Números de amostras para perdas: axial, 12; radial (700 a $\left.800 \mathrm{rpm}\right), 40$; radial (800 a $\left.900 \mathrm{rpm}\right), 32$.

${ }^{2}$ Números de amostras para velocidade: axial, 3; radial (700 a 800 rpm), 10; radial (800 a 900 rpm), 8.

Médias seguidas de mesma letra nas colunas indicam que os resultados não diferiram entre si, pelo teste de Tukey, a 5\% de probabilidade.

\section{CONCLUSÕES}

As colhedoras com idade entre zero e cinco anos apresentaram perdas menores do que as colhedoras com mais de seis anos de idade.

Não houve diferenças significativas entre as perdas de grãos e entre as rotações do cilindro em função da velocidade de avanço das colhedoras.

As colhedoras próprias apresentaram menores perdas quando comparadas com as colhedoras alugadas, enquanto, nas máquinas com sistema de trilha axial, as perdas foram significativamente menores em relação àquelas com sistema radial.

\section{REFERÊNCIAS}

ALVES SOBRINHO, T.; HOOGERHEIDE, H.C. Diagnóstico de colheita mecânica da cultura de soja no município de Dourados - MS. In: CONGRESSO BRASILEIRO DE ENGENHARIA AGRÍCOLA, 27, 1998, Poços de Caldas. Anais... Lavras: Sociedade Brasileira de Engenharia Agrícola, 1998. p.524.

COSTA, N.P.; MESQUITA, C.M.; OLIVEIRA, M.C. Efeito das velocidade de deslocamento e do cilindro de trilha da colhedora sobre as perdas de sementes na colheita de soja. Informativo Abrates, Londrina, v.12, n.1-3, p.15-19, 2002. 
COSTA, N.P.; MESQUITA, C.M.; MAURINA, A.C.; FRANÇA-NETO, J.B.; PEREIRA, J.E.; KRZYZANWSKI, F.C.; HENNING, A.A. Avaliação da qualidade de sementes e grãos de soja provenientes da colheita mecanizada,em diferentes regiões do Brasil. Engenharia Agrícola, Jaboticabal, v.22, n.2, p.211-19, 2002.

KUTZBACH, H.D. Combine development trends for the savanna regions. In: SIMPÓSIO SOBRE O CERRADO, 8., 1996, Brasília. Anais... Brasília: Embrapa, 1996. p.104-11.

MACHADO, A.L.T. Colhedoras de fluxo axial reduzem danos às sementes. Revista Seed News, v.2, n.4. Disponível em: <http://www.seednews.inf.br/portugues/seed74/artigocapa74.shtml>. Acesso em nov. 2004.

MESQUITA, C.M.; COSTA, N.P.; PEREIRA, J.E.; MAURINA, A.C.; ANDRADE, J.G.M. Caracterização da colheita mecanizada da soja no Paraná. Engenharia Agrícola, Jaboticabal, v.21, n.2, p.197-205, 2001a.

MESQUITA, C.M.; COSTA, N.P.; PEREIRA, J.E.; A.C.; ANDRADE, J.G.M. Perfil da colheita mecânica da soja no Brasil: perdas e qualidades físicas do grãos relacionadas à características operacionais. In: CONGRESSO BRASILEIRO DE ENGENHARIA AGRÍCOLA, 30., 2001, Foz do Iguaçu. Anais... Jaboticabal: Sociedade Brasileira de Engenharia Agrícola, 2001b. 1 CD ROM.

MESQUITA, C.M.; COSTA, N.P.; PEREIRA, J.E.; MAURINA, A.C.; ANDRADE, J.G.M. Perfil da colheita mecânica da soja no Brasil: safra 1998/1999. Engenharia Agrícola, Jaboticabal, v.22, n.3, p.398-406, 2002.

MESQUITA, C.M.; HANNA, M.A. Soybean threshing mechanics: I. Frictional rubbing by flat belts. Transactions of ASAE, St. Joseph, v.36, n.2, p.275-9, 1993.

MESQUITA, C.M.; MOLIN, J.P.; COSTA, N.P. Avaliação preliminar de perdas "invisíveis" na colheita da soja. In: CONGRESSO BRASILEIRO DE ENGENHARIA AGRÍCOLA, 27., 1998, Poços de Caldas. Anais... Lavras: Sociedade Brasileira de Engenharia Agrícola, 1998. p.106-8.

PINHEIRO NETO, R.; GAMERO, C.A. Efeito da colheita mecanizada nas perdas quantitativas de grãos de soja (Glycine max (L.) Merrill). Energia na Agricultura, Botucatu, v.14, n.1, p.69-81, 1999.

SALES, J.G.C.; CONSTANTIN, J. Interferência de plantas daninhas na colheita mecânica da soja (Glycine max (L.) Merril). In: CONGRESSO BRASILEIRO DE ENGENHARIA AGRÍCOLA, 29. 2000, Fortaleza. Anais... Jaboticabal: Sociedade Brasileira de Engenharia Agrícola, 2000. 1 CD ROM.

SILVA, R.P.; MESQUITA, H.C.B.; CAMPOS, M.A.O.; ZABANI, S. Avaliação de perdas na colheita mecanizada de soja em Uberaba - MG. In: CONGRESSO LATINO AMERICANO DE INGENERIA AGRÍCOLA, 5., 2002, La Habana, Cuba. Anais... La Habana: ALIA, 2002. 1 CD ROM.

SILVA, R.P.; PASCHOAL, M.A.; SERON , E.; CAIXETA, R.V. Determinação do índice de mecanização agrícola de Uberaba - MG, In: CONGRESSO BRASILEIRO DE ENGENHARIA AGRÍCOLA, 27., Poços de Caldas. Anais... Lavras: Sociedade Brasileira de Engenharia Agrícola, 1998. p.220-2. 